\title{
Chinese stock market cyclical regimes: 1991-2006
}

\author{
Wu Yan ${ }^{a}$, John G. Powell ${ }^{b}$, Jing Shi ${ }^{\text {c,d,* }}$, Wei Xu ${ }^{\text {e }}$ \\ a Jiangxi University of Finance and Economics, Nanchang 330013, China \\ ${ }^{\mathrm{b}}$ Massey University, Palmerston North, New Zealand \\ c Jiangxi University of Finance and Economics, Nanchang 330013, China \\ d The Australian National University, Canberra, Australia \\ e China Pharmaceutical University, Nanjing 210038, China
}

Received 17 May 2006; received in revised form 19 February 2007; accepted 15 March 2007 Available online 29 June 2007

\begin{abstract}
Chinese bull and bear market regimes are objectively identified and their statistical properties outlined. Chinese market cycles are extremely pronounced but have moderated as the market matures. Ex-ante trading rule tests indicate the usefulness of regime identification for Chinese investors.
\end{abstract}

(C) 2007 Elsevier B.V. All rights reserved.

Keywords: Stock market cycles; Bull and bear market regimes; Turning points

JEL classification: G12; G14

\section{Introduction}

Few economic phenomena attract more attention than bull and bear market cycles. The history and importance of bull and bear markets on Wall Street is well-known, but the cyclical behaviour of emerging stock markets is less well-established. China's stock markets are very new and very important, so an interesting question is to determine if cyclical regimes are more pronounced in younger markets like China's

\footnotetext{
* Corresponding author. School of Finance and Applied Statistics, The Australian National University, Canberra, ACT 0200, Australia. Tel.: +612 61254864; fax: +61262538322.

E-mail address: Jing.Shi@anu.edu.au (J. Shi).
} 
and whether cycles dampen as markets mature (see, e.g., Schaller and Van Norden, 2002; Pagan and Sossounov, 2003, hereafter PS). This note therefore objectively identifies and describes cyclical regimes in the Shanghai and Shenzhen stock markets.

The procedure used to formally identify bull and bear market regime turning points closely follows the algorithm developed by Bry and Boschan (1971) (hereafter BB) to determine peaks and troughs in the business cycle. An alternative procedure is Hamilton regime switching (see Hamilton, 1989; Schaller and Van Norden, 2002). Both methods attempt to identify economically significant regimes, but the BB method identifies regimes that correspond closely to standard perceptions of bull and bear market cycles (see, e.g., PS versus Schaller and Van Norden, 2002).

The BB procedure is implemented using monthly stock index data from Thomson Financial Datastream for January 1991 through December 2006 for the Shanghai Stock Exchange and April 1991 through December 2006 for the Shenzhen Stock Exchange. Once bull and bear market regimes are identified, the characteristics and statistical properties of bull and bear markets are outlined. Return differences between regimes are found to be much more pronounced than in traditional markets but have moderated lately as the market matures. The analysis concludes with an examination of the practical relevance of bull and bear market regime identification by conducting rolling out of sample tests of an exante trading rule that utilizes turning points once they are detected.

\section{Identifying bull and bear market regimes and their turning points}

The BB algorithm is implemented on unsmoothed stock index level data, with the decision not to smooth being due to the more volatile nature of financial markets (see, e.g, Canova, 1998; PS). Points that are higher or lower than those on five months either side are first identified (the window). Alternation of turning points is then enforced by selecting the highest of multiple peaks or the lowest of multiple troughs.

A complete cycle (peak to peak or trough to trough) must last at least twelve months; this requirement is slightly shorter than in other applications due to the more volatile nature of Chinese stock markets relative to developed markets (see also PS; Gonzalez et al., 2005). A phase (peak to trough or trough to peak) must span at least five months (the minimum phase length; see BB). When a month shows an absolute return greater than $20 \%$ then the minimum phase length requirement is ignored, since phases with market moves of this magnitude (including stock market crashes) are considered to be economically important. ${ }^{1}$

\section{Empirical results}

\subsection{Bull and bear market turning points and characteristics}

Chinese stock market regimes and their turning points are presented in Table 1. Important events in Chinese stock market history are illustrated, including the 1994 stock market crash. Table 1 displays extreme monthly mean return differences between bull and bear market regime phases, especially during the early history of the Chinese markets. Also of note, 8 bull and 7 bear market cycles are observed for the Shanghai Stock Exchange whereas only 7 bull and 6 bear market cycles are identified for Shenzhen,

${ }^{1}$ The financial press tends to identify a bull (bear) market when the stock market rises (falls) by more than 20\% (see PS). 
Table 1

Bull and bear markets: January 1991-December 2006

\begin{tabular}{llll}
\hline Peak to trough dates & & & Trough to peak dates \\
\cline { 4 - 5 } Date & $\begin{array}{l}\text { Mean phase capital return } \\
\text { (per month) }\end{array}$ & Date & $\begin{array}{c}\text { Mean phase capital return } \\
\text { (per month) }\end{array}$ \\
\hline Panel A: Shanghai & & & 0.1953 \\
May 1992-Oct 1992 & -0.1588 & Jan 1991-May 1992 & 0.2196 \\
Apr 1993-Jul 1994 & -0.0804 & Oct 1992-Apr 1993 & 0.0641 \\
Apr 1997-Sep 1997 & -0.0457 & Jul 1994-Apr 1997 & 0.0326 \\
May 1998-Feb 1999 & -0.0267 & Sep 1997-May 1998 & 0.0284 \\
Jun 2001-Jan 2002 & -0.0539 & Feb 1999-Jun 2001 & 0.0332 \\
Jun 2002-Oct 2003 & -0.0147 & Jan 2002-Jun 2002 & 0.0526 \\
Mar 2004-May 2005 & -0.0333 & Oct 2003-Mar 2004 & 0.0523 \\
Panel B: Shenzhen & & May 2005 & 0.0875 \\
Feb 1993-Jul 1994 & & & 0.0621 \\
Apr 1997-Sep 1997 & -0.0677 & Apr 1991-Feb 1993 & 0.0375 \\
May 1998-Feb 1999 & -0.0648 & Jul 1994-Apr 1997 & 0.0301 \\
May 2001-Jan 2002 & -0.0307 & Sep 1997-May 1998 & 0.0407 \\
Jun 2002-Oct 2003 & -0.0533 & Feb 1999-May 2001 & 0.0472 \\
Mar 2004-Jul 2005 & -0.0349 & Jan 2002-Jun 2002 & 0.0482 \\
\hline
\end{tabular}

Note: The last phase is incomplete, so the mean phase return is computed using data up to December 2006.

contrary to common belief that both markets have identical cycles. The major difference occurs at the start of the sample. While a severe bear market is identified during May 1992 to October 1992 in the Shanghai Stock Exchange, the whole period of January 1991 to February 1993 is identified as a very strong bull market in the Shenzhen Stock Exchange. Increased conformity therefore appears to accompany the moderation of bull and bear market cycles as the Chinese market matures.

Table 2 confirms the extreme return differences between Chinese bull and bear markets; the average return of bull markets is a remarkable $7.53 \%$ per month in Shanghai, for instance, whereas severe average losses of $-5.00 \%$ per month are observed in bear markets. The differences between bull and bear market returns are more than double those observed for more established stock markets (e.g., PS), and the differences are highly statistically significant. $t$-tests for return differences are conducted using a generated regressor (a bull market regime dummy that is highly persistent), so a 5\% cut-off significance level $t$-statistic is also reported that adjusts for the potential for spurious regression (see Ferson et al., 2003; Powell et al., 2006). Return differences remain highly significant even with this adjustment for spurious regression bias since the reported $t$-statistics exceed the cut-off $t$-statistics. Bull markets have much higher kurtosis and are therefore more prone to outliers than bear markets, and also display much higher return volatility.

\subsection{Trading rule results}

Bull and bear market turning points can be used in trading rules that utilize ex-ante information only, once account is taken of the five month lag with which turning points are detected (since the BB method 
Table 2

Characteristics of bull and bear markets

\begin{tabular}{lll}
\hline & Shanghai & Shenzhen \\
\hline Average duration of bull markets (months) & 15.13 & 16.86 \\
Average duration of bear markets (months) & 10.14 & 11.83 \\
$t$ test for difference between bull and bear markets & 1.06 & 0.94 \\
Average monthly return in bull markets & $7.53 \%$ & $5.42 \%$ \\
Average monthly return in bear markets & $-5.00 \%$ & $-4.28 \%$ \\
$t$ test for difference between bull and bear markets & $5.42 * * * *$ & $5.89 * * *$ \\
$5 \%$ cut-off $t$-statistics adjusted for spurious regression bias & 2.09 & 2.11 \\
Standard deviation of monthly returns in bull markets & $22.79 \%$ & $15.43 \%$ \\
Standard deviation of monthly returns in bear markets & $8.50 \%$ & $6.95 \%$ \\
$F$ test for difference between bull and bear markets & $7.19 * * *$ & $4.93 * * *$ \\
Maximum monthly return in bull markets & $177.23 \%$ & $85.33 \%$ \\
Maximum monthly return in bear markets & $20.89 \%$ & $12.36 \%$ \\
Minimum monthly return in bull markets & $-30.90 \%$ & $-21.97 \%$ \\
Minimum monthly return in bear markets & $-31.15 \%$ & $-19.46 \%$ \\
Kurtosis of monthly return in bull markets & 33.24 & 7.80 \\
Kurtosis of monthly return in bear markets & 2.37 & -0.01 \\
Skewness of monthly return in bull markets & 5.10 & 2.22 \\
Skewness of monthly return in bear markets & -0.52 & $120 / 192$ \\
Months in bull markets & $86 / 120$ & $16 / 72$ \\
Months with positive returns in bull markets & & $118 / 189$ \\
Months with positive returns in bear markets & $77 / 118$ & $15 / 71$ \\
\hline Month with & \\
\hline
\end{tabular}

Months with positive returns are obtained by including months with zero capital returns. Phase duration is the number of continuous months in each phase. $* * *$ denotes significance at $1 \%$ level, $* *$ denotes significance at $5 \%$ level.

requires that index values five months to either side be examined before a particular month can be identified as a turning point). Out of sample rolling tests of trading rules provide an indication of the usefulness of bull market turning points for investors who are interested in market timing. The trading rule purchases shareholdings five months after a bull market turning point, with investors borrowing the equivalent of $100 \%$ to invest in the stock market when a buy signal is received. Share investments are sold five months after bear market turning points, and the proceeds are reinvested in safe short-term deposits until the next buy signal is received. The trading strategy therefore provides riskier returns that equal two times the stock index rate of return minus the deposit rate when invested in shares, and safe short term deposit returns otherwise. Trading costs are incorporated into the analysis and are set equal to the maximum brokerage rate during the sample period $(0.3 \%$ of the trade value) plus the prevailing stamp tax

Table 3

Summary statistics for trading rule performance

\begin{tabular}{llllll}
\hline & Shanghai & & & \multicolumn{2}{c}{ Shenzhen } \\
\cline { 2 - 3 } & Passive & Trading rule & & Passive & Trading rule \\
\hline Average monthly trading rule return & 0.0286 & 0.0389 & & 0.0176 & 0.0276 \\
Standard deviation of monthly trading rule return & 0.1971 & 0.2422 & & 0.1368 & 0.1800 \\
Sharpe ratio & 0.1451 & 0.1607 & & 0.1284 & 0.1530 \\
\hline
\end{tabular}


(a transaction tax that was $0.3 \%$ of the trade value at the start of the sample period in 1991 and is periodically adjusted by the government). ${ }^{2}$

Table 3 reports trading rule returns that would have been generated during the sample period and compares them to returns generated by a passive index buy and hold strategy. Trading rule returns are $36 \%$ and $57 \%$ higher than passive returns in Shanghai and Shenzhen, respectively (i.e. 0.0389 per month vs. 0.0286 in Shanghai) with a slightly higher level of risk (i.e. 0.2422 vs. 0.1971 in Shanghai), thereby providing a superior Sharpe ratio relative to a passive strategy. ${ }^{3}$ The trading rule tests therefore indicate that $\mathrm{BB}$ method bull and bear market trading rule strategies can be useful for Chinese investors with an interest in aggressive market timing.

\section{Conclusion}

Bull and bear market regimes are identified for one of the newest and most important emerging markets. Return differences between bull and bear market regimes are huge, especially compared to those of traditional markets, but have moderated somewhat lately, perhaps reflecting a recent maturing of the Chinese market. Identification of market regimes can provide useful information to Chinese investors interested in aggressive market timing strategies.

\section{References}

Bry, G., Boschan, C., 1971. Cyclical Analysis of Time Series: Selected Procedures and Computer Programs. National Bureau of Economic Research, New York.

Canova, F., 1998. Detrending and business cycle facts. Journal of Monetary Economics 41, 475-512.

Ferson, W.E., Sarkissian, S., Simin, T.T., 2003. Spurious regressions in financial economics? Journal of Finance 58, $1393-1413$.

Gonzalez, L., Powell, J.G., Shi, J., Wilson, A., 2005. Two centuries of bull and bear market cycles. International Review of Economics and Finance 14, 469-486.

Hamilton, J.D., 1989. A new approach to the economic analysis of nonstationary time series and the business cycle. Econometrica 57, 357-384.

Pagan, A.R., Sossounov, K.A., 2003. A simple framework for analysing bull and bear markets. Journal of Applied Econometrics $18,23-46$.

Powell, J.G., Shi, J., Smith, T., Whaley, R., 2006. Spurious dichotomous variable regressions in financial economics. Australian National University working paper.

Schaller, H., Van Norden, S., 2002. Fads or bubbles? Empirical Economics 27, 335-362.

\footnotetext{
2 The minimum brokerage rate during the sample period is only $0.027 \%$. The stamp tax was set at $0.3 \%$ on November 23 , 1990 and was raised in May 1997 to $0.5 \%$ due to severe speculative behavior. It has since been lowered to $0.4 \%$ on June 12 , $1998,0.3 \%$ on June 1, 1999, 0.2\% on November 16, 2001, and 0.1\% on January 24, 2005 (see www.chinatax.gov.cn and http:// finance.sina.com.cn/).

3 The Sharpe ratio equals the mean return minus the risk-free rate divided by the return standard deviation. Short term deposit interest rate data are also obtained from Thomson Financial Datastream.
} 